\title{
NOTE ON THE DETECTION OF ADULTERATION OF FRESH MILK BY DILUTED CONDENSED MILK.
}

\author{
By H. Droop Richiond and L. K. Boseley.
}

(Read at the Meeting, May 3rd, 1893.)

Some five years ago a Dairy Farmers' Association offered a gold medal for the solution of this problem. Their chemist advised them that it was not possible, and he had no hope of its ever being done. The medal was not awarded.

Faber (loc. cit.) has devised a method of detecting the adulteration by the diminished amount of soluble albumin in heated milk, and we have been able to amply confirm his results.

We have found the albumin to vary from 0.41 to 0.45 per cent. in fresh milks, which is within Faber's limits, $0.35-0.45$. The reduction of the rotary power of the milk sugar will also be of great assistance. We would recommend analysts to estimate the milk sugar by the polariscope, and if it falls below 52 per cent. of the solids not fat to make careful gravimetric determinations of the milk sugar by Fehling's solution; to satisfy themselves that the deficiency is not due to lactic fermentation, by acidity estimations; and to estimate the soluble albumin by Sebelien's method.

A discrepancy between the gravimetric and polarimetric estimations of the milk sugar will afford considerable evidence that the milk has undergone heating, and if the soluble albumin is also low the evidence will be almost conclusive.

The limits in fresh milks may be taken as albumin 0.35 per cent, milk sugar and lactic acid 55 per cent. of the solids not fat, and the gravimetric and the polarimetric estimations of milk sugar will not differ more than 0.15 per cent.

The diphenylamine test for nitrates would also afford strong corroborative evidence if impure well water (common on farms) had been used. We operate as follows: Curdle the milk by heating and adding the least possible excess of acetic acid; dissolve a little diphenylamine in pure sulphuric acid (1 c.c.), and allow a few 
drops of the serum to flow over the surface. A blue colour is characteristic of nitric acid; we have obtained the reaction in a milk to which 5 per cent. of water has been added.

\section{Discussion.}

Mr. Faber was very much interested in seeing that Messrs. Richmond and Boseley had taken up the method of analysis which he had some years ago brought before the Society, and which had been proposed by Subelien. He (Mr. Faber) had only time on that occasion to make a few estimations of albumin in milk-boiled or fresh. He quite agreed with the authors of the paper that the amount of albumin found by Sebelien's method must be absolutely unreliable-that is to say, if the latter meant soluble albumin. He thought, even if Sebelien meant all the albumin present, either precipitated or soluble, the figures were somewhat overstated.

Dr. J. A. Voelcker thought it undesirable to draw a distinction between skim milk and skimmed milk, because it seemed to him that such a distinction would certainly never hold good: not only on account of the similarity of the words, but because all minute descriptions of this kind seemed to him impracticable. As to the test based upon the detection of uitrates and nitrites in the water used, it was quite a frequent occurrence to find water which contained no nitrates at all, and then the test would be useless.

$\mathrm{Mr}$. R. Bodmer, referring to the determination of sugar, wished to know if the citric acid inversion was the only portion of the Stokes and Bodmer process used by them. Many years ago he analyzed a sample of Swiss condensed milk, and had found that it was absolutely free from cane sugar. He would like to know whether the authors of the paper had found the same.

Mr. H. Droop Richmond: Yes, in some cases.

Mr. Otto Hehner expressed the pleasure he felt at seeing $\mathrm{Mr}$. Boseley (a former pupil of his) come forward with a paper. He was glad that the authors had been more successful with the diphenylamine test than he (Mr. Hehner) had been. His difficulty had been that sulphuric acid alone produced an objectionable colour with the milk direct, or with the residue obtained by extracting the milk-solids with alcohol and evaporating the latter. He observed that $\mathrm{Mr}$. Richmond allowed the milk to be tested to flow over the sulphuric acid, avoiding mixture. He noted that the authors drew a distinction between skimmed milk and separated milk. He had learned with surprise that this question had arisen in a court of law, in the prosecution of a vendor of an article labelled "Skimmed Condensed Milk." The sample in question was plainly and honestly labelled in large letters " Skimmed Condensed Milk," the Analyst who gave evidence stating that the contents did not consist of skimmed milk, but of scparated milk. The vendor was fined. He (Mr. Hehner) thought that the point was not worthy of the consideration of Public Analysts, who had far more important matters to attend to. The difference between milk that had been hand-skimmed and such that was machine-skimmed was so small that it was not worth talking about in an article like condensed milk, or to make a point of it in a prosecution under the Sale of Food and Drugs Act. Certainly, in most cases, machine-skimmed milk contained a little less fat than hand-skimmed milk, but, on the other hand, separated 
milk was quite fresh, while hand-skimmed milk was more or less sour. There were, at the same time, very numerous analyses of skimmed milk on record which showed that often hand-skimming was at least as effective to remove the cream as machine work, and the Analyst could not, therefore, be in a position to prove by determination of the fat alone what method of skimming had been employed, unless, indeed, the whole of the fat were removed, which was not the case in the sample subject to prosecution. No two separators worked exactly alike, and even the same machine gave different results on different days. Therefore, if the Analyst concerned carricd out his contention to the logical extent, he would have to insist upon the name of the machine used being stated, as well as the number of revolutions of the separator. His decided opinion was that, due notice having been given by a plain and honest label that the fat had been removed by skimming, the purchaser was not prejudiced, no matter whether the skimming had been done by hand or by separator, or more or less completely. The purchaser had no right to expect in skim-milk any fat at all, and any that was left in the skim-milk was really a present to him and a loss to the manufacturer of the condensed milk. No ordinary purchaser expected any fat in skim-milk at all. He thought the point was a mere quibble, and not exactly fair to the merchant who tried to conduct his business honestly. At the present time there was no consensus of opinion, even among experts, in this matter, and unless by common consent a distinction was made between skimmed and separated milk, it was not right to spring such a point in a court of law upon the vendor. He was strongly opposed to the sale of skimmed condensed nilk, unless due notice was given to the buyer, but such notice having been given plainly and unmistakably, it appeared to him quite immaterial how and to what extent the skimming had been effected. The absurdity of the position was made plain by the attempt of the authors of the paper to make a distinction between skimmed milk and skim-milk.

Mr. Cassal disagreed with Mr. Hehner. He could not admit that because Public Analysts had a number of other things to deal with, therefore this matter should be left alone. The Public Analyst had to deal with the things which were submitted to him. It happened that certain public Authorities were in the habit of deciding what articles should be analyzed, and it was not advisable for a Public Analyst to object to that course of action. The persons responsible for the taking of samples in such cases as those referred to were the Committee of the Authority. It invariably threw suspicion on a public officer if he raised objections to any course which was desired by a Committee or a Board. The case referred to was only one among many. These articles were generally sold under the name of "Condensed Milk," and in some corner of the label, printed in small letters, there was a statement containing the word "skimmed," the word being introduced on some other part of the label than that containing the principal title. Statements of that sort no one could possibly defend. If a condensed milk was practically devoid of fat, that fact should be stated fully on the label, and should form part of the title of the article. The use of the word "skimmed" was not a sufficient disclosure of the real nature of such an article, and the label that Mr. Hehner had alluded to did not contain a sufticient disclosure. Why was it that a certain class of vendors desired to adhere to the use of the word "skimmed " and would not use the word "separated," which 
accurately disclosed the nature of the article? The only answer was that the word "skimmed" conveyed a more favourable impression, and that, in fact, the article so described would be thought better than it really was. Did anyone suppose for a moment that the manufacturers of these articles employed an army of persons to handskim their milk before they condensed them? It was a matter of common knowledge that these articles were produced by means of separators, and that they could only be so produced. When Mr. Hehner said that there was but very little difference between the percentages of fat found in milk that had had cream removed by hand and in milk treated by a separator, he forgot also to point out that it was possible to get any results one liked with a separator. It depended on how far it was worked; and the comparison which he made between the percentages of fat were entirely beside the mark, because, in the first place, the figures leferred to had been collected from all sources-they were not authenticated, and there was no doubt that many had been obtained by obsolete processes and unreliable persons; and, in the second place, the matter in hand was the comparison between legitimately hand-skimmed milk and milk which had been almost completely deprived of fat, a result which had unquestionably been attained by means of a separating machine.

Mr. Allen quite agreed that the point which had been raised was one of very great interest to the Society of Public Analysts; and the opposite views taken by Mr. Hehner and Mr. Cassal showed how much need there was for discussion. A point which had not been referred to was the misleading statement to be found on the labels of many brands of condensed milk respecting the amount of water required to be added. This was often very greatly overstated, with the consequence that the consumer had milk of far less nourishing power than he supposed.

Mr. E. J. Bevan said that he did not agree with Mr. Hehner, and not altogether with Mr. Cassal. It might be true, as Mr. Hehner had said, that a large number of so-called separated milks certainly showed a higher percentage of fat than skimmed milks. Everything depended upon the way in which one operated. But taking the average composition of separated milks and the average composition of skimmed milks, there was not a shadow of a doubt that the proportion of fat removed in the case of the separated milk was much greater than in the other case. This went a great way towards showing that there was a definite distinction between the two. Some of the samples labelled "Condensed Skimmed Milk" which he had received contained a very small proportion of fat, so small that he could have no doubt that they had been treated in a separator.

Dr. Voelcker hoped that Public Analysts would not attempt to draw distinctions between so-called skimmed and separated milks. He regarded skimmed or separated milk as milk from which the fat had been removed, and in his opinion it was a matter of accident as to how much had been removed. If it could be said that milk always contained a definite quantity of fat when skimmed by hand, and another definite quantity when separated by machine, then clear distinctions could be drawn, but not otherwise.

Mr. Faber said that separated milk contained an extremely low amount of fat, which would not exceed from 1 to 3 per cent. in well-managed dairies. If milk had 
to be hand-skimmed before it commenced turning sour, so as to be fit for condensing, it would be found that the skimmed milk contained sometimes as much as 2 per cent. of fat, very often over 1 per cent. He considered that there was a great deal of difference between hand-skimmed milk and separated milk. There was a point in favour of separated milk which might be inentioned, and that was that by separating, not only was the fat removed, but the impurities also to a very large extent. On the inside of the separator bowl an aggregation of very dirty slimy black matter was formed, which contained almost all the dirt present in the milk, and which was thus kept out of separated milk. The value of skimmed milk, as a nourishment, varied to a certain extent with the contents of fat. With regard to the label, if it merely stated that a portion of the fat had been removed, and the amount removed was found to be something like 95 per cent., then he considered it a misleading label, but if the contents of the tins were described on the label as " Skimmed Milk," then he thought this was a sufficient disclosure.

Mr. Cassal thought that Dr. Voelcker's remarks were much to the point, as they admitted the accuracy of his (Mr. Cassal's) contention. Dr. Voelcker had said that the amount of fat left by hand-skimming was uncertain. He had also said that the amount of fat which might be left in milk after using a separator was uncertain. But there was one thing which was certain, and which he understood that Dr. Voelcker and $\mathrm{Mr}$. Hehner admitted without reserve, and that was that when there was practically no fat at all, when 90 per cent. of it had been abstracted, then there was no doubt whatever that the abstraction had been effected by a separator. This was all that he (Mr. Cassal) required. Mr. Faber had published in The Analyst some years ago a paper in which he advocated the use of the term "separated" for these articles, and in which he said that the word "skirnmed" did not afford a sufficient description of them.

Mr. Faber admitted that he had in the paper referred to said that the term "condensed separated milk" would be a more correct description than if it was merely mentioned that "part of the cream" had been abstracted, but he had not used the word "separated" as against the word "skimmed." The difference was between printing on the label in large letters " Skimmed Milk" or "Separated Milk," and of calling the milk with such a name as, for instance, "Goat Brand," and then in small letters adding that "part of the cream" has been abstracted.

Mr. Cassal gathered, from what Mr. Faber had just said, that he adhered to his original recommendation, and that he thought it would be better for the public if these articles were described by their correct name, as "Condensed Separated Milk."

Mr. Allen said he had been struck with the ingenious and powerful manner in which the arguments had been put on both sides. With leference to the whole subject, he would point out that the Government had promised a Select Committee to consider Dr. Cameron's Bill now before the House of Commons as soon as it had passed its second reading. In view of the fact that the Government appeared to be desirous of dealing with the subject of adulteration, although they could not do it very thoroughly on the basis of such a Bill as Dr. Cameron's, it was important that Analysts should be agreed as to how articles should be labelled. He was 
afraid that there were not very many people among the lower classes who knew the meaning of the words "separated" milk, and, for his own part, he preferred the term "skimmed" milk. He thought "skimmed milk" covered the whole ground and inclucled separated milk, which might be regarded as mechanically skimmed milk. There might be less fat in the mechanically than in the hand skimmed milk, but it would be difficult to establish a definite distinction between them which would stand critical examination. He thought the distinction attempted to be drawn between the words "skim" and "skimmed" was a quibble. They ought to base their action on much broader grounds than these, which were objections only worthy of lawyers. With regard to the estimation of nitrogen in the copper precipitate obtained by Ritthausen's method, he thought that if the precipitate-including the filter-paper, if they liked-were treated by Kjeldahl's process, a much more reliable result would be obtained than by igniting the precipitate and regarding the loss as proteids.

Mr. Richmond, in reply, said that, with regard to Mr. Allen's suggestion of estimating the nitrogen in the Ritthausen precipitate, he had sometimes done so ; it seemed to be a more satisfactory method of estimating proteids by actual weighing than by calculation from the nitrogen; the percentage of nitrogen in casein was not known with absolute accuracy, Hammarsten giving 15.65 per cent. and Chittenden and Painter 15.9 per cent., and the error of the factor would be probably as great as the error of weighing. A remark had been made to the effect that in the adulteration of fresh milk by condensed skimmed milk it was not reliable to depend on the presence of nitrates. In their paper they had brought this forward as affording further and independent evidence of adulteration; if nitrates were found it was very strong, and, in fact, the only direct, evidence that the milk had been mixed with water (containing nitrates). Mr. Hehner had asked if they had examined samples of milk which had been purposely adulterated with diluted condensed milk. They had not done so. In a diluted condensed milk they had found a deficiency of 0.8 per cent. of sugar. This paper was not intended as an exhaustive one, it was only called a " note," and they thought that the evidence would induce others to make experiments. The chief part of the discussion had turned upon what they (the authors of the papers) considered a somewhat unimportant pointwhether "skimmed" and "separated" milk were synonymous terms. Mr. Boselcy and he beld no very strong opinion on this point, and had introduced it for the sake of eliciting the opinion of the Society ; the subject had some practical interest, as cases had lately occurred. They had stated subsequently that if the words "Skim Milk" were used on the tins, it might be difficult to obtain a conviction, but between "skimmed" and " separated" milk there was a difference. He observed the point was not seen by some. There were two distinct things--skimmed milk and separated milk. Two statements to the contrary had been brought before the meeting, i.e., König's analysis and Dr. Voelcker's experiments at shows. $\mathrm{He}(\mathrm{Mr}$. Richmond) did not think that the results given by a machine fitted up at a show could be taken as a fair specimen of what the machine could do, as it was worked frequently under unsuitable conditions, and by operators whose minds would be occupied by details unconnected with the working of the machine. König's 
figures were extracted from all kinds of sources, and the majority of the determinations made by methods now admitted to be inexact. With regard to the extremely low percentage of fat sometimes found in hand-skimmed milk, that low percentage could be obtained if desired, but it could not be done on a commercial scale. If one considers that the milk in the tins is always fresh, he thought there could be no shadow of doubt that skim milk would contain more fat than separated milk. Personally, he could echo a remark of Mr. Hehner's, that it was not a serious infringement of the Act, and that there were other adulterations which were mole in need of being stopped. 